\title{
Abnormal plasma lipids profile in women with post-adolescent acne
}

\author{
Krystyna Romańska-Gocka, Magdalena Woźniak, Elżbieta Kaczmarek-Skamira, Barbara Zegarska
}

Department of Cosmetology and Esthetic Dermatology, Collegium Medicum in Bydgoszcz, Nicolaus Copernicus University in Torun, Poland

Adv Dermatol Allergol 2018; XXXV (6): 605-608

DOI: https://doi.org/10.5114/ada.2018.77612

\begin{abstract}
Introduction: Acne vulgaris is a multifactorial chronic inflammatory disease that is increasingly recognized in adult women.

Aim: To investigate a relationship between plasma lipids profile and acne in women and a correlation between selected clinical features of acne (severity, age of onset, location of lesions and the presence of comedones) and lipids profile.

Material and methods: Sixty-four adult women with post-adolescent acne and 20 healthy controls were included in the study. Plasma total cholesterol (TC), triglycerides (TG), high-density lipoprotein cholesterol (HDL-C) and lowdensity lipoprotein cholesterol (LDL-C) levels were determined in all the subjects.

Results: Adult women with acne had statistically significantly increased levels of TC, TG and LDL-C compared to healthy controls $(p<0.05)$. The level of HDL-C did not differ between the two groups. There was no relationship between higher levels of TC, TG and LDL-C and a clinical picture of acne.

Conclusions: Acne in adult women is likely to be associated with increased levels of TC, TG and LDL-C. This abnormality seems to be important in the pathogenesis of adult acne and could be a result of high fatty acid diet. Performing a lipid profile examination in women with acne should be taken into account when screening patients and followed by appropriate dietary recommendations.
\end{abstract}

Key words: acne, women, lipids.

\section{Introduction}

Acne is a chronic inflammatory disease with multifactorial pathogenesis. It affects an increasing number of adult women, especially active, working women in their 20s to 40s [1]. Post-adolescent acne can be divided into two groups: persistent acne (type 1), which is a continuation of acne from adolescence, and lateonset acne (type 2) with first occurrence of symptoms after the age of 25 years, accounting for approximately $80 \%$ and $20 \%$ of cases, respectively [2]. It is generally mild to moderate in severity and presents with more inflammatory lesions and fewer comedones compared to adolescent acne [3].

The causes of post-adolescent acne have not been completely clarified. Androgens are considered the major factor involved in the pathogenesis [4]. Acne probably results from an exacerbated response of the pilosebaceous unit to the normal circulating androgen levels
[3]. Acne can be triggered or worsened by endogenous and exogenous factors, including genetic predisposition, hormone concentrations, diet, smoking, stress, and exposure to ultraviolet light [5]. Little is known about the relationship between blood lipids and acne. It is possible that the increase level of total cholesterol (TC), low density lipoprotein cholesterol (LDL-C) and triglycerides (TG) could play a role in post-adolescent acne pathogenesis, as well as the decreased level of high density lipoprotein cholesterol (HDL-C), although further research is necessary to elucidate this [6].

\section{Aim}

The aim of the study was to investigate a relationship between plasma lipids profile and acne in women and a correlation between selected clinical features of acne (severity, age of onset, location of lesions and the presence of comedones) and lipids profile.

Address for correspondence: Krystyna Romańska-Gocka MD, PhD, Department of Cosmetology and Esthetic Dermatology, Collegium Medicum, Nicolaus Copernicus University, 5 Kurpińskiego St, 85-096 Poland, phone: +48 605 413 908, e-mail: dermatol@poczta.onet.pl Received: 1.07.2017, accepted: 11.10.2017. 


\section{Material and methods}

Ethical approval was obtained from the Ethics Committee of Collegium Medicum in Bydgoszcz, Poland, before the initiation of the study. Informed written consent was obtained from all the participants. A total of 84 women were enrolled to the study, 64 women with acne (either persistent or late-onset) at the age of 20-46 years, and 20 healthy women as controls, at the age of 21-46 years. The control group consisted of volunteers who have visited our outpatient clinic for reasons not related to acne. At the beginning of the study, clinical examination was performed. It included the assessment of acne severity, according to the Hayashi et al. grading system [7]. Based on the number of inflammatory eruptions on a half of the face, acne was scored as: 0-5 mild, 6-20 moderate, or 21-50 severe. The type of acne was established: type 1 (beginning in adolescence) or type 2 (first symptoms after 25 years old). Finally, other clinical features of acne were assessed, such as location of acne lesions (only on the face or together in facial and extrafacial locations) and the presence of comedones. Patients had taken neither oral isotretinoin nor oral antibiotics for at least 6 months before the study. None of our patients took any hypolipidemic drugs in the past. None of patients was obese, body mass index (BMI) was in the normal range. The familial history of lipid disturbances was unknown. Patients did not take oral contraceptives for at least 6 months before the study.

\section{Statistical analysis}

Statistical analysis was carried out using Statistica 12.5 software. Results are expressed as mean \pm standard deviation (SD). The parameters of descriptive statistics such as: arithmetic mean $(x)$, standard deviation (SD), minimal and maximal value (min. and max.) have been shown. Analysis of distribution of the tested parameters was performed using the Shapiro-Wilk test. Parameters with a normal distribution were developed using t-test,

Table 1. Clinical features of acne in the studied group

\begin{tabular}{llcc}
\hline \multirow{2}{*}{\begin{tabular}{l} 
Clinical features of acne \\
\multirow{2}{*}{$\begin{array}{l}\text { Severity } \\
\text { of acne }\end{array}$}
\end{tabular}} & Mild & \multicolumn{1}{c}{$\begin{array}{c}\text { Number } \\
\text { of subjects }\end{array}$} & Percentage \\
\cline { 2 - 4 } & Moderate & 21 & 33 \\
\cline { 2 - 4 } & Severe & 32 & 50 \\
\hline \multirow{2}{*}{$\begin{array}{l}\text { The onset } \\
\text { of acne }\end{array}$} & Type 1 & 37 & 17 \\
\cline { 2 - 4 } & Type 2 & 27 & 58 \\
\hline Location of & Face & 53 & 83 \\
\cline { 2 - 4 } symptoms & Face, chest and back & 11 & 17 \\
\hline Presence of & No comedones & 35 & 55 \\
\cline { 2 - 4 } comedones & Presence & 29 & 45 \\
& of comedones & & \\
\hline
\end{tabular}

while parameters not having normal distribution, using Mann-Whitney test. The differences were considered significant if the $p$ value obtained was $p<0.05$.

\section{Results}

In total, 84 women were enrolled in the study. The mean age of the acne group was 25.5, and of the control group 28.5. Among 64 cases, moderate acne was established as the most frequent (50\%), mild acne concerned $33 \%$ and severe acne $17 \%$ of the patients. Fifty-eight percent of our patients reported the onset of acne in teenage years (type 1), $42 \%$ of patients - after 25 years of life (type 2 ). In the majority of patients, acne lesions were located only on the face (83\%), whereas in $17 \%$ of them symptoms were present on the face, chest and back. Besides inflammatory lesions, comedones were present in $55 \%$ of cases. The clinical features of acne in the examined group are presented in Table 1.

Plasma TC, TG and LDL-C levels were significantly higher in women with acne than in healthy controls $(p<0.05)$. Regarding the level of HDL-C, there was no significant difference between cases and controls, as shown in Table 2.

Results for parameters such as TC, TG and LDL-C in patients from the studied group were higher and differences amounted to $15.1 \mathrm{mg} / \mathrm{dl}$ for TC (mean for the studied group was $182.2 \mathrm{mg} / \mathrm{dl}$ compared to the mean of $167.1 \mathrm{mg} / \mathrm{dl}$ for the control group), for TG, the result was higher by $20 \mathrm{mg} / \mathrm{dl}$ ( $96.6 \mathrm{mg} / \mathrm{dl}$ vs. $76.6 \mathrm{mg} / \mathrm{dl}$ ), and for $\mathrm{LDL}-\mathrm{C}$, the result was higher by $18.9 \mathrm{mg} / \mathrm{dl}(101.5 \mathrm{mg} / \mathrm{dl}$ vs. $82.6 \mathrm{mg} / \mathrm{dl}$ ).

The higher levels of TC, TG and LDL-C, as well as the level of HDL-C, were independent of age and not connected with the clinical features of acne, such as the severity of acne, the age of onset, location of lesions and the presence of comedones (Table 3).

\section{Discussion}

Acne is a common skin problem, affecting women at higher rates than men. In the majority of cases of women, post-adolescent acne is mild to moderate $[8,9]$, comprising mainly inflammatory lesions [1]. In our studies, mild to moderate acne was found the most frequently, too. It affected a total of $83 \%$ of women up to 46 years old, but besides inflammatory lesions, we have also found comedones in high percentage in 55\% of cases.

In almost all the patients, acne represents persistence of the disease, rather than the new-onset acne [10]. We observed that $42 \%$ of the studied patients with acne, reported the late onset of their disease, thus confirming an increasing incidence of the problem among adult women, contrary to Cunliffe opinion [10]. Similarly, 
Table 2. Plasma lipids profile analysis of acne patients and controls

\begin{tabular}{|c|c|c|c|c|c|c|}
\hline Parameter & Patients & Mean & SD & Min. & Max. & $P$-value \\
\hline \multirow[t]{2}{*}{ Age } & Acne patients & 27.5 & 6.1 & 20.0 & 46.0 & $0.46^{u}$ \\
\hline & Controls & 30.3 & 9.2 & 21.0 & 46.0 & \\
\hline \multirow[t]{2}{*}{$\mathrm{TC}[\mathrm{mg} / \mathrm{dl}]$} & Acne patients & 182.2 & 29.3 & 115.9 & 258.9 & $0.04^{\top}$ \\
\hline & Controls & 167.1 & 24.8 & 132.8 & 213.8 & \\
\hline \multirow[t]{2}{*}{ TG [mg/dl] } & Acne patients & 96.6 & 35.6 & 49.9 & 212.1 & $0.01^{\cup}$ \\
\hline & Controls & 76.6 & 21.6 & 47.8 & 144.1 & \\
\hline \multirow[t]{2}{*}{ LDL-C [mg/dl] } & Acne patients & 101.5 & 23.2 & 58.9 & 170.2 & $0.01^{U}$ \\
\hline & Controls & 82.6 & 29.8 & 11.5 & 135.5 & \\
\hline \multirow[t]{2}{*}{$\mathrm{HDL}-\mathrm{C}[\mathrm{mg} / \mathrm{dl}]$} & Acne patients & 62.3 & 12.0 & 30.7 & 93.6 & $0.26^{\top}$ \\
\hline & Controls & 59.1 & 10.6 & 44.8 & 79.5 & \\
\hline
\end{tabular}

SD - standard deviation, min. - minimal value, max. - maximal value, TC - total cholesterol, TG - triglycerides, LDL-C-low-density lipoprotein cholesterol, HDL-C - high-density lipoprotein cholesterol. U-Mann-Whitney test, $T$-t-test.

Table 3. Analysis of the relationship between the lipids profile and selected clinical features of acne

\begin{tabular}{|c|c|c|c|c|c|}
\hline \multirow[t]{2}{*}{ Parameter } & \multicolumn{2}{|c|}{ Type 1} & \multicolumn{2}{|c|}{ Type 2} & \multirow[t]{2}{*}{$P$-value } \\
\hline & Mean & SD & Mean & SD & \\
\hline Age [years] & 26.5 & 5.9 & 29.0 & 6.0 & $0.103^{\mathrm{U}}$ \\
\hline $\mathrm{TC}[\mathrm{mg} / \mathrm{dl}]$ & 178.7 & 25.3 & 186.9 & 33.9 & $0.269^{\top}$ \\
\hline $\mathrm{TG}[\mathrm{mg} / \mathrm{dl}]$ & 93.7 & 36.4 & 100.6 & 34.8 & $0.291^{\mathrm{U}}$ \\
\hline $\mathrm{LDL}-\mathrm{C}[\mathrm{mg} / \mathrm{dl}]$ & 100.2 & 23.2 & 103.3 & 23.6 & $0.491^{\cup}$ \\
\hline $\mathrm{HDL}-\mathrm{C}[\mathrm{mg} / \mathrm{dl}]$ & 60.5 & 8.5 & 64.7 & 15.4 & $0.175^{\top}$ \\
\hline Extra-facial location: & & & & & \\
\hline Age [years] & 27.8 & 6.2 & 26.1 & 5.3 & $0.395^{u}$ \\
\hline $\mathrm{TC}[\mathrm{mg} / \mathrm{dl}]$ & 183.6 & 30.4 & 175.2 & 23.3 & $0.389^{\top}$ \\
\hline $\mathrm{TG}[\mathrm{mg} / \mathrm{dl}]$ & 96.5 & 37.7 & 96.9 & 24.4 & $0.972^{\mathrm{U}}$ \\
\hline LDL-C [mg/dl] & 102.7 & 23.9 & 96.1 & 20.0 & $0.394^{u}$ \\
\hline $\mathrm{HDL}-\mathrm{C}[\mathrm{mg} / \mathrm{dl}]$ & 62.7 & 12.3 & 60.0 & 10.5 & $0.501^{\top}$ \\
\hline Presence of comedone: & & & & & \\
\hline Age [years] & 26.8 & 5.0 & 28.3 & 7.2 & $0.688^{u}$ \\
\hline $\mathrm{TC}[\mathrm{mg} / \mathrm{dl}]$ & 179.5 & 31.6 & 185.5 & 26.4 & $0.420^{\top}$ \\
\hline $\mathrm{TG}[\mathrm{mg} / \mathrm{dl}]$ & 91.7 & 38.3 & 102.5 & 31.7 & $0.073^{U}$ \\
\hline LDL-C [mg/dl] & 99.9 & 24.1 & 103.5 & 22.4 & $0.453^{u}$ \\
\hline $\mathrm{HDL}-\mathrm{C}[\mathrm{mg} / \mathrm{dl}]$ & 62.9 & 13.1 & 61.5 & 10.8 & $0.649^{\top}$ \\
\hline
\end{tabular}

$U$ - Mann-Whitney test, $T-t$-test, SD - standard deviation.

Ekiz et al. reported late-onset acne in $47.8 \%$ of studied patients [9].

The persistency of acne among adult women and the difficulties in treatment need further exploration of possible pathogenetic factors. Sebum production is considered as one of the principal factors involved in acne development. The importance of hormonal influence on sebum secretion is also confirmed in clinical and experimental studies. However, studies have not shown any clear pattern of abnormalities, suggesting that hormonal receptors expressed in sebocytes and keratinocytes may be more sensitive to normal levels of androgens [11].

It is possible that one of important features of postadolescent acne in women is an abnormal lipid profile. This could be a result of diet. Some studies revealed that adults with acne have higher levels of TC, TG and LDL-C, whereas the level of HDL-C is normal or even lower in comparison with healthy controls $[6,9,12,13]$. We dis- 
covered that, according to some previous publications, the plasma levels of TC, TG and LDL-C were significantly higher in women with acne than in healthy controls and that the HDL-C level did not differ in the two compared groups. We did not observe a lower level of HDL-C in acne patients contrary to other authors $[6,9,12]$. Contrary to results of El-Akawi et al., we did not confirm that the higher level of TC was observed only in obese women. In our group of patients there were no obese patients. We did not observe the relationship between the lipid profile and the severity of acne, contrary to Bakry et al. studies in which higher values of TC together with lower values of HDL-C were significantly associated with severe acne [6]. El-Akawi et al. concluded that the increased level of $\mathrm{LDL}-\mathrm{C}$ is related to severe acne [12], whereas Jiang $\mathrm{H}$ et al. observed a correlation between increased TC and LDL-C levels and severe acne in women [13]. Ekiz et al. did not find a significantly higher level of TG among acne patients [9].

We did not find any data evaluating the correlation between the lipid profile and the age of onset of acne in the literature. Our studies did not detect a significant relationship between the results and the onset of acne.

The influence of diet on acne aggravation has been already discussed in the literature [14]. There are no papers indicating the importance of low cholesterol diet in acne. Studies concentrate on the high-glycemic load diet and dairy food, especially milk, enhancers of insulin/IGF-1 signaling leading to acne aggravation $[15,16]$. Cholesterol is a sterol, present in animal cells and body fluids, an important constituent of cell membranes and precursor for the biosynthesis of steroid hormones, including cortisol, aldosterone, estrogen and testosterone. It must be attached to certain protein complexes called lipoproteins in order to be transported through the bloodstream [17]. Triglycerides are the main constituent of body fat. Total cholesterol levels may affect the development of acne, because both adrenal and gonadal androgens are synthetized from cholesterol derived from the plasma [6].

Dietary modification remains the first-line therapy for lower plasma cholesterol [17]. It has been known for a long time that the amount and type of fat in the diet have an effect on blood lipid concentration [18]. Based on patients' reports, we noted that they consume a lot of carbohydrates a day, diet rich in saturated fatty acids and low in polyunsaturated fatty acids, and that they live in persistent stress. Our results indicated that women with acne have significant changes in plasma lipids. We conclude that the measurement of blood lipid levels should be kept in mind when screening women with acne. The proper diet should be recommended as an additional treatment option. It should decrease total energy and animal fat intake and increase the consumption of vegetables and fruit [19].

\section{Conflict of interest}

The authors declare no conflict of interest.

\section{References}

1. Dreno B, Thiboutot D, Layton AM, et al. Large-scale international study enhances understanding of an emerging acne population: adult females. J Eur Acad Dermatol Venereol 2015; 29: 1096-106.

2. Holzmann R, Shakery K. Postadolescent acne in females. Skin Pharmacol Physiol 2014; 27 Suppl. 1: 3-8.

3. Ramos-e-Silva M, Ramos-e-Silva S, Carneiro S. Acne in women. Br J Dermatol 2015; 172 Suppl: 20-6.

4. Preneau S, Dreno B. Female acne - a different subtype of teenager acne? J Eur Acad Dermatol Venereol 2012; 26: 277-82.

5. Albuquerque RGR, Rocha MAD, Bagatin E, et al. Could adult female acne be associated with modern life? Arch Dermatol Res 2014; 306: 683-8.

6. Bakry AO, El Shazly RMA, El Farargy SM, Koth D. Role of hormones and blood lipids in the pathogenesis of acne vulgaris in non-obese, not-hirsute females. Indian Dermatol Online J 2014; 5 Suppl. 1: 9-16.

7. Hayashi N, Akamatsu H, Kawashima M. Establishment of grading criteria for acne severity. J Dermatol 2008; 35: 255-60.

8. Choi CW, Lee DH, Kim HS, et al. The clinical features of late onset acne compared with early onset acne in woman. J Eur Acad Dermatol Venereol 2011; 25: 454-61.

9. Ekiz O, Balta I, Unlu E, et al. Assessment of thyroid function and lipid profile in patients with postadolescent acne in a Meditteranean population from Turkey. Int I Dermatol 2015; 54: 1376-81.

10. Cunliffe WJ. Management of adult acne and acne variants. J Cutan Med Surg 1998; 2: S3.

11. Dreno B. Treatment of adult female acne: a new challenge. J Eur Acad Dermatol Venereol 2015; 29 Suppl. 5: 14-9.

12. El-Akawi Z, Abdel-Latif N, Abdul-Razzak K, Al-Aboosi M. The relationship between blood lipids profile and acne. J Health Science 2007; 53: 596-9.

13. Jiang H, Li ChY, Zhou L, et al. Acne patients frequently associated with abnormal plasma lipid profile. J Dermatol 2015; 42: 296-9.

14. Pappas A. The relationship of diet and acne. Dermatoendocrinology 2016; 1: 262-7.

15. Danby FW. Acne: diet and acnegenesis. Indian Dermatol Online J 2011; 2: 2-5.

16. Melnik BC. Diet in acne: further evidence of the role pf nutrient signaling in acne pathogenesis. Acta Derm Venerol 2012; 92: 228-31.

17. Brownawell AM, Falk MC. Cholesterol: where science and public health policy intersect. Nutr Rev 2010; 68: 355-64.

18. Norum KR. Dietary fat and blood lipids. Nutr Rev 1992; 50: 30-7.

19. Melnik BC. Dietary intervention in acne. Attenuation of increased mTORC1 signaling promoted by Western diet. Dermatoendocrinology 2012; 4: 20-32. 